\title{
Formando professoras de ciências para o diálogo intercultural na pesquisa e no ensino a partir de um trabalho colaborativo
}

\author{
Geilsa Costa Santos Baptista* \\ Dirlane Gomes e Silva**
}

\begin{abstract}
Resumo
O objetivo do estudo qualitativo foi mapear a possibilidade de formação de duas professoras de ciências para o diálogo intercultural a partir de um trabalho colaborativo envolvendo intervenções pedagógicas em salas de biologia de uma escola do estado da Bahia. A metodologia incluiu vídeo-gravação, transcrição, mapas de eventos, seleção de episódios e análise de conteúdo. Os resultados indicam tentativas, mas não abordagens dialógicas durante as intervenções. O estudo permitiu repensar aspectos voltados para as interações dialógicas que ocorrem durante os processos de ensino e aprendizagem e na pesquisa científica com relação à formação inicial e continuada dos professores de ciências.

Palavras-chave: Ensino de ciências; Diálogo intercultural, Formação de professores para a diversidade cultural.
\end{abstract}

\section{Preparing science teachers for intercultural dialogue in research and teaching from a collaborative work}

\begin{abstract}
The purpose of the qualitative study was to map training possibilities of two science teachers for intercultural dialogue based on a collaborative work involving pedagogical interventions in biology classrooms of a school in the state of Bahia. The methodology included video-recording, transcription, event maps, episode selection and content analysis. The results indicate attempts, but not dialogic approaches during interventions. The study allowed to rethink aspects related to the dialogical interactions that occur during the teaching and learning processes and in the scientific research regarding the initial and continued training of science teachers.
\end{abstract}

Keywords: Science education; Intercultural dialogue, Teacher training for cultural diversity.

\section{Introdução}

Sabe-se que o desenvolvimento do conhecimento humano tem relação direta com suas experiências com os demais seres humanos e com o mundo ao seu redor. Disso, possivelmente, decorre a opinião de muitos educadores e pesquisadores de que o ensino de ciências deve considerar e respeitar a diversidade de ideias que são trazidas pelos estudantes para as salas de aula como forma de facilitação e contextualizações das aprendizagens. Como facilitação, porque muitas das temáticas que são trabalhadas como conteúdos de ensino também são inerentes aos meios sociais dos estudantes, como, por exemplo, as questões ambientais e saúde. Como contextualizações, porque ao considerar os saberes culturais dos estudantes, os professores poderão estabelecer com eles relações dialógicas interculturais, nas quais poderão demarcar o discurso da ciência e perceber como o mesmo difere e/ou se assemelha aos demais discursos culturais presentes nas salas de aula. Porque o diálogo é uma relação de comunicação na qual os saberes são apresentados e justificados em seus contextos de origem e validade.

\footnotetext{
*Endereço Eletrônico: geilsabaptista@ gmail.com

***Endereço Eletrônico: dirlanegs@ gmail.com
}

O diálogo no ensino de ciências, segundo Lopes (1999), é a exposição da pluralidade de razões por parte dos sujeitos. Logo, dialogo envolve argumentação, que significa exposição das justificações a partir dos dados em que se baseiam (OSBORNE et al., 2001). No diálogo, as razões que levam os indivíduos a pensarem como pensam serão expostas, consideradas e avaliadas por critérios de validade e legitimidade que são próprios dos seus contextos (LOPES, 1999).

Sendo assim, torna-se imperativo que o professor favoreça a argumentação nas suas salas de aula. A argumentação na educação científica "[...] pode facilitar o processo de aprendizagem de ciência e contribuir para desenvolver o pensamento crítico e, ainda, melhorar a tomada de decisão pelo cidadão [...]" (CONRADO et al., 2015, p. 1). Argumentações nas aulas de ciências são importantes para que sejam apresentados os distintos e/ou semelhantes significados culturais ali presentes, tanto por parte da ciência, representada pelos professores, quanto dos meios sociais onde os estudantes estão imersos e tem as suas origens.

Para a promoção de momentos argumentativos nas salas de aula de ciência, 
entretanto, é necessária a formação dos professores adequada para esta finalidade, pois, é fato, a maneira como esses profissionais exercem as suas práticas pedagógicas está intimamente relacionada às suas formações - seja dentro das universidades (formação inicial), seja durante a própria docência (formação continuada) -, podendo influenciar as aprendizagens dos estudantes. Dito de maneira mais específica, é preciso que os professores realizem reflexões epistemológicas sobre a ciência que ensinam. Por reflexões epistemológicas entende-se as reflexões sobre o conjunto de valores e de pressupostos inerentes ao desenvolvimento do conhecimento científico, o que requer a consideração da história, da filosofia e da sociologia da ciência (DIBATTISTA; MORGESE, 2013). De igual forma, que busquem investigar e compreender as epistemologias dos conhecimentos trazidos pelos estudantes para os contextos das salas de aula e como elas são importantes para as suas vidas.

Certamente, o professor de ciências que tem formação sobre a epistemologia da ciência, que ensina e busca investigar e compreender os saberes culturais dos estudantes, não terá problemas para o favorecimento de argumentações, porque buscará a adoção de estratégias que facilitem a exposição das diferentes vozes, estabelecendo entre elas as inúmeras relações culturais existentes, sejam elas de semelhanças e/ou de diferenças. Isso conduzirá os estudantes à delimitação dos contextos de origem e de aplicabilidade dos conhecimentos envolvidos, científicos e dos seus próprios meios socioculturais.

Todavia, melhorias na formação dos professores de ciências requerem mudanças na formação dos formadores desses professores, no sentido de que também realizem reflexões sobre a sua própria docência, incluindo aí reflexões epistemológicas sobre a maneira como concebem a ciência e lidam com outros saberes presentes nas salas de aula (BAPTISTA, 2014). Para Donald Schön (1983), ação docente baseada no princípio da reflexividade dialoga com a própria prática, analisando-a a fim de produzir novos saberes que lhes serão necessários para que melhorias ocorram no exercício da profissão. Disso, acredita-se serem necessárias parcerias colaborativas entre o meio acadêmico e a escola, entre os professores que já atuam dentro dos espaços escolares e os professores das universidades, pois isto obviamente ampliará as possibilidades de investigações e análises sobre as concepções de ciências, demais saberes culturas e próprias práticas pedagógicas em ambos os níveis de ensino voltada para a diversidade cultural
(BAPTISTA, 2014).

O objetivo deste artigo é apresentar e discutir os resultados de um estudo qualitativo cujo objetivo central foi mapear a possibilidade de formação de uma formadora de professores de ciências (primeira autora) e de uma professora de biologia (segunda autora) para a diversidade cultural a partir de trabalho colaborativo que envolveu a construção e aplicação de um recurso e sequência didática para o diálogo intercultural em salas de biologia de uma escola pública do estado da Bahia.

\section{Metodologia}

\section{Os sujeitos envolvidos no trabalho colaborativo}

$\mathrm{O}$ estudo ora relatado teve natureza qualitativa e foi desenvolvido em 2009 de maneira colaborativa entre a primeira autora (formadora de professores de biologia na Universidade Estadual de Feira de Santana - UEFS) e a segunda (como professora de biologia da rede pública de ensino do estado da Bahia). A duração total de trabalho foi de 132 horas, distribuídas em 20 encontros intercalados que tiveram duração de 5 horas cada um. Para isto, foram utilizados os espaços físicos da UEFS e de um Colégio do estado da Bahia, onde a segunda autora atua como professora de biologia. Ambas as instituições estão localizadas na cidade de Feira de Santana (BA).

A primeira autora, é professora na UEFS há 14 anos, ministra aulas na graduação de Estágio Supervisionado em Ensino de Biologia, Pluralidade Cultural e Inclusão no ensino de ciências. Além disto, atua como professora no Programa de PósGraduação em Ensino, Filosofia e História das Ciências (Universidade Federal da Bahia em convênio com a UEFS) e coordena o Grupo de Investigações em Etnobiologia e Ensino de Ciências (UEFS), onde desenvolve e orienta estudos voltados para o ensino e a formação de professores de ciências para a diversidade cultural. A segunda autora, além de professora de biologia da rede pública de ensino do estado da Bahia, é mestre em botânica pela UEFS e secretária de meio ambiente na cidade Ipecaetá, Bahia. Atua como docente na rede pública e particular de ensino há 20 anos e como secretária de meio ambiente há 3 anos.

Parte-se da hipótese de que o trabalho colaborativo de elaboração e aplicação de um recurso e sequencia didática poderia contribuir para a formação continuada de ambas as professoras envolvidas, na perspectiva do 
professor como investigador da sua própria prática (SCHÖN, 1983). Especialmente por gerar oportunidades para investigações e reflexões críticas e, por conseguinte, para ampliação dos saberes pedagógicos, podendo incidir na tomada de decisões futuras, tanto nas pesquisas quanto no ensino voltado para o diálogo intercultural. Dito em outras palavras, o trabalho colaborativo permitiria interações entre a pesquisa e a própria prática pedagógica, gerando possibilidades de reflexões que poderão conduzir ao desenvolvimento profissional docente. Segundo Ponte (2008), no trabalho colaborativo, os participantes trabalham de maneira conjunta em prol de um objetivo comum. No trabalho colaborativo entre professores de ciências, a parceria envolve planejar, implementar e refletir sobre uma série de questões que envolvem as ações didáticas e terminam por influenciar no desenvolvimento e formações desses profissionais (JONES, 2008). Na pesquisa ora relatada, o objetivo comum do trabalho colaborativo foi mapear as possibilidades de formação continuada das professoras envolvidas no tocante ao respeito e à consideração da diversidade cultural.

Assim, buscou-se a elaboração e aplicação de um recurso e sequência didática para ser aplicado com estudantes do segundo ano do ensino médio de um colégio público do estado da Bahia, localizado na cidade de Feira de Santana, onde a professora de Biologia desenvolvia as suas atividades de ensino em 2009. Segundo dados obtidos junto à direção do colégio sob estudo e conversas informais entre a professora e os estudantes nas salas de aula, uma parte significativa dos sujeitos que frequentam o referido colégio são agricultores e/ou filhos de agricultores e são provenientes de pequenas cidades circunvizinhas a Feira de Santana (BA), que sobrevivem, basicamente, da agricultura familiar (Jaíba, Ipuaçú, Santo Estevão e Antônio Cardoso).

\section{A construção do recurso didático e os objetivos da sua utilização na sala de aula de Biologia}

Para a construção do recurso e sequência didática, inicialmente foi levada em conta a realidade agrícola dos estudantes do colégio onde atuava a professora de Biologia. Com base nisso, buscou-se discutir quais seriam as possibilidades de recursos didáticos que melhor contribuiriam para aulas baseadas no diálogo intercultural, entre a linguagem científica da biologia e a linguagem inerente ao meio sociocultural dos estudantes agricultores, considerando, também, que nos espaços sociais das salas de aula daquele colégio também estariam presentes estudantes não agricultores. Disso, optou-se por uma narrativa, que, segundo Galvão (2005), consiste na descrição de uma história, podendo representar em educação um poderoso método de investigação, reflexão e formação pedagógica, seja na forma oral ou escrita. A narrativa permitiria, portanto, a apresentação de situações cotidianas aos estudantes e, ao mesmo tempo, abriria possibilidades de aproximações dos seus saberes aos saberes científicos da biologia.

A temática escolhida para compor a narrativa foi pragas agrícolas da região e seus controles, a qual foi previamente indicada pelos estudantes à professora de biologia como sendo de seu interesse, visto que a maioria deles, por serem agricultores, enfrentam sérios problemas e dificuldades para combater espécies de insetos que danificam as plantas por eles cultivadas. É importante destacar que o termo praga agrícola é utilizado pelos estudantes para fazer referência aos animais, ou outros seres vivos como bactérias e fungos, que causam danos à produção agrícola.

$\mathrm{Na}$ Figura 1, encontra-se a narrativa elaborada colaborativamente, a qual aborda o controle biológico de pragas agrícolas da região e as consequências do uso de agrotóxicos. Basicamente, por meio de uma linguagem coloquial e também científica, conta a história de dois amigos que se encontram na zona rural. $\mathrm{O}$ primeiro começa a queixar-se de pragas que estão atacando as plantas por ele cultivadas, pedindo ao outro que lhe contasse o que faz para combatê-las. O segundo amigo conta que usa produtos químicos e o primeiro orienta-lhe que esse não seria um procedimento ideal, nem para o próprio homem e nem para a natureza ao seu redor, indicando-lhe o uso de produtos naturais como o controle biológico. 
Figura 1. Narrativa elaborada colaborativamente com abordagem sobre pragas agrícolas.

\section{Um problema para dois compadres}

Dois compadres se encontram no banco:

- Oi compadre! Quanto tempo faz que não nos vemo!

- Pois é compadre. Como vai meu afilhado? E comadre?

- Vão bem!

- Faz tanto tempo que a gente não se vê compadre! Me conte, e a cidade grande, como está?

- Compadre, a cidade grande vai bem, mas eu prefiro aqui na roça, porque é mais tranquilo viu! Aqui a gente tem de tudo...

- Já que faz tempo que não nos vemos que tal então marcar um final de semana na minha roça? Aí botamos o papo em dia.

- Ótima ideia! Quer dizer: senão for atrapalhar, né?

- Que atrapalhar que nada compadre é uma satisfação! Nós temos muita consideração pelo senhor e tem lugar para todo mundo. Iremos no próximo sábado pela manhã, logo bem cedinho. Olhe compadre, vamos tomar leite fresco, comer coalhada, pescar no rio, e tomar suco das minhas acerolas.

- Olhe compadre, nada de caçar, pois temos que respeitar a natureza.

No sábado pela manhã...

- Ô de casa! Cheguei compadre!

- Vou pedir para servir um leitinho fresco e uma coalhada para nós. No almoço vamos saborear galinha caipira e doce de leite na sobremesa. Depois do almoço, vamos pescar e nadar no rio.

Os compadres almoçaram e depois foram descansar um pouco. Antes do descanso surgiu uma conversa:

- Veja só compadre: as formigas estão atacando as minhas plantas: capim, hortaliça, as minhas árvores e os pés de acerola já não aguenta mais o pulgão! Mais o pior mesmo compadre é a formiga! O compadre acredita, essas tais de formigas cortadeiras estão arrasando com tudo! Elas comem as folhas todinhas deixando as plantas sem crescimento até que morrem. De tudo isso, compadre, o incrível é que elas saem voando aos montes! Isso dá mais ou menos uma vez por ano e daí aparecem mais e mais formigas... Aparece formigueiro em todos os cantos da roça compadre. Um tipo de buraco que elas fazem que chega a fazer um lombo no chão. É mesmo uma praga!

- Que coisa compadre!

- Mas não se preocupe com isso agora! Vamos dormir um pouco aqui na rede e depois o senhor me ajuda a cuidar das formigas e do pulgão, pode ser? Quero saber como é que o senhor faz.

- É compadre, mas só de falar me dá desespero. Tô perdendo tudo! E o pulgão? Esse nem se fala, é uma miséria! Acredita compadre que vi meu pé de acerola, que estava lindo, com as folhas todas brancas e enrugadas e sem frutas. Justo as frutas que a gente aqui faz suco que os médicos dizem que tem muita vitamina $\mathrm{C}$, que é bom pra não gripar! Mas vou mesmo parar de falar, depois conversaremos mais.

Após o descanso, os compadres saíram aos arredores da roça dizendo:

- Olhe compadre, eu já fui comprar alguns produtos praguicidas na loja do fazendeiro... produtos?

- Esses produtos são muito perigosos compadre, além de serem caros. Como é que o senhor usa esses

- Eu aplico direto nas pragas...

- Meu Deus! O senhor vai se matar e matar todo mundo!

- Não me diga compadre! Mas por quê?

- Esses produtos são perigosos, têm que ter muito cuidado. Quando a vaca como o capim, ele entra no corpo da vaca, contamina o leite, o doce de leite e até o cocô da vaca sai contaminado! As suas galinhas vivem pastando, comendo as formigas, as acerolas e o capim contaminado. Além do mais, quando chove a chuva deve levar tudo isso para dentro do rio. Coitado dos peixes! A gente não pode mais nadar nem pescar neste rio, comer peixe nem pensar!

- Vamos ficar doentes compadre? Vamos acabar com natureza? Meu Deus! O que eu faço? Como é que eu vou fazer agora para me livrar das pragas, sem prejudicar a natureza e poder ganhar meu dinheirinho?

- Compadre, compadre não se desespere! O senhor já ouviu falar que só não tem jeito para a morte? Tudo tem solução compadre...

- Eu tenho umas receitas da cidade grande que é tiro e queda. E pra variar, não faz mal nenhum, até um menino pode manejar. É tudo natural compadre! Mas compadre, a parte melhor eu ainda vou lhe contar.

- Não me diga que aqui na cidade vende nas farmácias? 
- Oxente! Muito melhor que isso compadre. O senhor não vai gastar nem um tostãozinho!

- Mas isso é bom demais! E o senhor cobra quanto para me dar essas receitas?

- Mas que pergunta é essa? Assim o senhor até me ofende!

- Mas por que compadre?

- Essas receitas a gente não esconde não. A gente faz questão de passar um para o outro.

- Que maravilha! Isso é que é viver bem! Assim eu não quero mais sair daqui da roça como tava querendo viu? Aqui eu tenho tudo, mas essas praga tem me agoniado o juízo! Agora com essa sua ideia, melhor ainda! E compadre, já que as receitas ajudam a agricultura, eu tive uma excelente ideia compadre.

- Me diga? Qual é?

- Nós vamos reunir todo esse povão e vamos ensinar para todo mundo.

- Essa ideia vale a vida compadre! É muito boa! É maravilhosa! Vai ajudar a vida das pessoas, porque muita gente daqui ta passando necessidade por causa das tais pragas...

- Vou ensinar algumas receitas pro senhor. Olhe compadre, vou fazer melhor: Lá na minha região o pessoal montou um manual, um livrinho com essas receitas. Eu acho que eu até tenho um aí na minha mala. Espere um pouco que vou buscar... Achei compadre. Vamos ler ele juntos?

- Sim, compadre!

- Então vamos lá ler:

\section{Para as formigas cortadeiras (Acromyrmex spp):}

Para combater as formigas cortadeiras o agricultor pode buscar ajuda das aves que, de um modo geral, são excelentes predadoras de insetos. Elas conseguem atacar formigueiros, especificamente as rainhas novas no ar ou na terra quando estão cavando ninho. O gavião (Polyborus plancus) é um bom exemplo de controle biológico para as formigas cortadeiras. Ele consegue ingerir, em média, $37 \mathrm{~kg}$ de insetos por ano. Desse modo, é muito importante não matar esses animais, deixando-os livres aos arredores dos espaços agrícolas para que possam predar as formigas.

As galinhas (Gallus gallus) também são excelentes predadoras de formigas e, assim como os gaviões, devem ser deixadas livres nos espaços agrícolas para que possam se alimentar das formigas.

\section{Para os Pulgões (Aphis spiroecola):}

Para o controle de pulgões podem ser utilizadas as joaninhas (Coccinella septempunctata). As joaninhas fêmeas colocam seus ovos geralmente nas folhas e ramos e, após alguns dias, surgem as larvas que iniciam as atividades de predadoras. Na fase adulta, as joaninhas também se alimentam de pulgões. Assim, para combater os pulgões, o agricultor pode colocar as joaninhas, facilmente encontradas na natureza, na base da planta que está sendo atacada. Um fato importante é que o controle dos pulgões também ajuda a controlar as formigas, que se alimentam de substâncias doces. Os pulgões quando sugam a seiva da planta liberam essas substâncias.

Os fungos Beauveria bassiana e Metarizium anisopliae, que podem ser encontrados a venda, também podem ser utilizados para combater os pulgões porque eles causam doenças nesses insetos levando-os à morte. Sempre que possível aplicar após chuva. Sua eficiência é muito maior. É importante colocar esses organismos sempre misturado com água e no final da tarde, pois o sereno propicia a umidade do ar e favorece o desenvolvimento dos fungos.

Após a construção da narrativa, foi elaborada uma sequência didática para o seu uso com os estudantes. Dado o curto espaço de um artigo científico, essa sequência não será aqui apresentada na íntegra, e serão pontuados apenas os conteúdos abordados e os objetivos das aulas. Os conteúdos abordados foram: (i) Conhecimentos locais e conhecimentos científicos (conceitos e relações); Agricultura (conceitos, tipos e importâncias); (ii) Pragas agrícolas (conceitos, tipos, consequências e soluções); (iii) Desenvolvimento sustentável (conceitos e relações com a agricultura). O objetivo geral das aulas foi: (i) Identificar as relações entre o conhecimento científico e o tradicional no tocante às pragas agrícolas e seu controle biológico, considerando aí as condições de vida e sua preservação, bem como a ideia de desenvolvimento sustentável. Com base nesse objetivo geral, foram pontuados os seguintes objetivos específicos: - Conceituar agricultura, seus tipos e importâncias; - Conceituar pragas agrícolas, tipos, consequências e soluções; Conceituar desenvolvimento sustentável relacionando à ideia de sustentabilidade ambiental, econômica e cultural.

Durante todo o processo de elaboração do recurso e da sequência didática ocorreram discussões no tocante aos aspectos teóricos considerados como mais relevantes para o ensino e a pesquisa em ensino de ciências sensível à 
diversidade e diálogo intercultural, a saber: (1) A etnobiologia ${ }^{1}$, conceitos, seu objeto de estudo, procedimentos metodológicos de pesquisa $\mathrm{e}$ contribuições para a investigação dos saberes culturais dos estudantes ligados à natureza; (2) A história e a filosofia das ciências e suas contribuições para a compreensão da natureza da ciência e demarcação de saberes no ensino de ciências; (3) A relevância da investigação da prática pedagógica e dos saberes culturais dos estudantes para o diálogo intercultural no ensino de ciências. As seguintes bibliografias, entre outras, foram utilizadas para leitura: Matthews (1995); El-Hani (2001); Gil-Pérez (2001); Cobern e Loving (2001); Rosa e Schnetzler (2003); ElHani e Mortimer (2007).

\section{Coleta e análise dos dados}

De posse da narrativa escrita, foram realizadas intervenções pedagógicas numa turma de segundo ano do ensino médio de uma escola pública do estado da Bahia. Essas intervenções pedagógicas foram filmadas (CARVALHO, 2006) e a escolha dessa técnica para coleta de dados se deu por acreditar-se que ela permite capturar de forma mais ampla os diferentes aspectos com relação às interações realizadas nas salas de aula e, do mesmo modo, uma mínima interferência por parte do pesquisador (MARTINS, 2006).

A professora cumpriu um total de quatro intervenções subdivididas em dois momentos (aulas geminadas) que aconteceram em duas semanas seguidas. $\mathrm{O}$ procedimento para a filmagem dessas aulas consistiu na instalação de uma câmera de vídeo num dos cantos da frente da sala de aula e do posicionamento da primeira autora no fundo dessa sala, controlando uma segunda câmera. A professora de biologia ficou livre, transitando por todos os espaços das salas de aula.

$\begin{array}{crlr}\text { As } & \text { filmagens } & \text { das } & \text { intervenções } \\ \text { pedagógicas } & \text { também } & \text { foram } & \text { assistidas }\end{array}$ colaborativamente com o objetivo de abrir espaços para reflexões e discussões. Partiu-se do pressuposto de que discussões sobre as intervenções nas realidades das salas de aula permitiriam reflexões sobre a pesquisa e própria prática pedagógica no tocante ao diálogo intercultural. Os dados obtidos desse momento foram anotados em um diário de campo e serviram de base para as discussões que serão apresentadas a seguir, no item Resultados e Discussões.

Após as filmagens terem sido assistidas e discutidas, elas foram transcritas para um editor de texto (CARVALHO, 2006) com o propósito de construção de mapas de eventos, isto é, esquemas das principais partes das aulas. Segundo Amaral e Mortimer (2006), os mapas de eventos, ou mapas de atividades, constituem recortes que representam os contextos característicos das atividades desenvolvidas nas salas de aulas e contribuem para a escolha dos episódios ou eventos que permitirão as análises das interações nas salas de aula. Com o intuito de garantir a privacidade dos estudantes, seus nomes, que foram citados nas salas de aula pela professora participante, não são mencionados nas transcrições. Os estudantes são identificados conforme a sequência das suas falas durante todas as aulas, isto é, Estudante 1 (estudante que falou primeiro), Estudante 2 (segundo estudante em falar), e assim, sucessivamente.

Com base nos mapas dos eventos, buscouse a seleção de um episódio de ensino e sobre esse a Análise de Conteúdo (BARDIN, 2006). Nesse momento, buscou-se interpretar os significados gerais das comunicações entre a professora e os estudantes, isto é, se foram dialógicas ou de autoridade (MORTIMER; SCOTT, 2002). Com isso, seria possível evidenciar como a construção e aplicação do recurso e sequência didática de maneira colaborativa teria ou não contribuído para a prática pedagógica da professora de biologia com relação ao diálogo intercultural e, por conseguinte, para a sua formação nesse sentido. De igual forma, para a formação da pesquisadora, enquanto formadora de professores de ciências no tocante ao diálogo intercultural.

\section{Resultados e Discussões}

Participaram das intervenções pedagógicas 35 estudantes, dos gêneros masculino e feminino, com idades que variaram entre 16 e 21 anos. Esses estudantes estavam dispostos em grupos, cada grupo composto por 7 ou 8 estudantes. A distribuição por grupos aconteceu segundo as escolhas dos próprios estudantes, segundo as suas afinidades.

A seguir, nos quadros 1 e 2, os mapas dos principais eventos ocorridos durante essas intervenções. 
Quadro 1. Mapa dos eventos ocorridos nas duas primeiras aulas com duração de $57 \mathrm{~min} 40$ s

\begin{tabular}{|c|c|c|c|c|}
\hline $\begin{array}{l}\text { Tempo } \\
\text { (min. e } \\
\text { seg.) }\end{array}$ & Atividades & Temas & $\begin{array}{l}\text { Ações dos } \\
\text { Participantes }\end{array}$ & Comentários \\
\hline $\begin{array}{l}10 \mathrm{~min} . \\
50 \mathrm{~s}\end{array}$ & $\begin{array}{l}\text {-Formação de grupos } \\
\text { para leitura e } \\
\text { discussão do material } \\
\text { didático. }\end{array}$ & $\begin{array}{l}\text {-Exposição oral pela } \\
\text { professora: apresentação } \\
\text { dos objetivos das aulas. }\end{array}$ & & $\begin{array}{l}\text { - Silencio da turma; } \\
\text { - A professora antecipou-se na } \\
\text { apresentação do conteúdo na } \\
\text { narrativa antes da sua leitura. }\end{array}$ \\
\hline $\begin{array}{l}30 \\
\min .37 s\end{array}$ & -Leitura da narrativa. & $\begin{array}{l}\text {-Pragas agrícolas } \\
\text { (conceitos, tipos, } \\
\text { consequências e } \\
\text { soluções). }\end{array}$ & $\begin{array}{l}\text {-Distribuição da } \\
\text { narrativa aos grupos } \\
\text { pela professora; } \\
\text { - Leitura silenciosa da } \\
\text { narrativa pelos } \\
\text { estudantes nos grupos. }\end{array}$ & $\begin{array}{l}\text { - Intenso barulho durante a } \\
\text { distribuição da narrativa; } \\
\text { - Os estudantes leram a narrativa } \\
\text { silenciosamente; } \\
\text { - Por várias vezes a professora } \\
\text { interrompeu as leituras dos } \\
\text { estudantes dando explicações. }\end{array}$ \\
\hline $\begin{array}{l}16 \mathrm{~min} . \\
13 \mathrm{~s}\end{array}$ & $\begin{array}{l}\text { - Episódio: } \\
\text { Resolvendo uma } \\
\text { questão: Qual a } \\
\text { melhor forma de } \\
\text { combater as pragas } \\
\text { agrícolas, natural ou } \\
\text { química? }\end{array}$ & $\begin{array}{l}\text { - Conhecimentos locais } \\
\text { e científicos (conceitos e } \\
\text { relações) } \\
\text {-Agricultura (conceitos, } \\
\text { tipos e importâncias); } \\
\text {-Controle biológico de } \\
\text { pragas e } \\
\text { sustentabilidade; } \\
\text { - Agrotóxicos e } \\
\text { inseticidas naturais. }\end{array}$ & $\begin{array}{l}\text { - Apresentação das } \\
\text { ideias pelos grupos. } \\
\text { - Questionamentos } \\
\text { pela professora e } \\
\text { pelos estudantes } \\
\text { acerca da temática; } \\
\text { - Orientação para as } \\
\text { atividades das } \\
\text { próximas aulas. }\end{array}$ & $\begin{array}{l}\text { - Os estudantes fizeram barulhos } \\
\text { e demonstraram bastante } \\
\text { inquietação realizando perguntas } \\
\text { sobre os conteúdos apresentados } \\
\text { na narrativa; } \\
\text { - A professora apresentou-lhes } \\
\text { novas perguntas, mas não houve } \\
\text { problematização de ideias. }\end{array}$ \\
\hline
\end{tabular}

Quadro 2. Mapa dos eventos ocorridos nas duas últimas aulas com duração de $1 \mathrm{~h} 2 \mathrm{~min} 25 \mathrm{~s}$.

\begin{tabular}{|c|c|c|c|c|}
\hline $\begin{array}{l}\text { Tempo } \\
\text { (min. e } \\
\text { seg.) }\end{array}$ & Atividades & Temas & $\begin{array}{l}\text { Ações dos } \\
\text { Participantes }\end{array}$ & Comentários \\
\hline $\begin{array}{l}5 \mathrm{~min} . \\
15 \mathrm{~s}\end{array}$ & - Formação de grupos & & $\begin{array}{l}\text { - Deslocamento das } \\
\text { cadeiras para } \\
\text { formação dos grupos e } \\
\text { discussões. }\end{array}$ & $\begin{array}{l}\text { - Os estudantes fizeram muito } \\
\text { barulho para formação dos } \\
\text { grupos. }\end{array}$ \\
\hline $\begin{array}{l}17 \mathrm{~min} . \\
48 \mathrm{~s}\end{array}$ & $\begin{array}{l}\text {-Apresentação da } \\
\text { representação do } \\
\text { primeiro grupo das } \\
\text { representações } \\
\text { elaboradas com base } \\
\text { na leitura da } \\
\text { narrativa. }\end{array}$ & $\begin{array}{l}\text { - Pragas agrícolas, } \\
\text { controle químico e } \\
\text { biológico; } \\
\text { - Cadeia alimentar e } \\
\text { relações com inseticidas. }\end{array}$ & $\begin{array}{l}\text { - Apresentação oral e } \\
\text { escrita de um poema; } \\
\text {-Questionamentos } \\
\text { pela professora. }\end{array}$ & $\begin{array}{l}\text { - Os estudantes demonstram } \\
\text { insegurança para apresentação; } \\
\text { - Intenso barulho entre os } \\
\text { demais estudantes, que } \\
\text { interrompiam a apresentação do } \\
\text { grupo; } \\
\text { - Houve risadas durante a } \\
\text { apresentação do grupo, que não } \\
\text { foram mediadas pela professora. }\end{array}$ \\
\hline $\begin{array}{l}20 \mathrm{~min} . \\
5 \mathrm{~s}\end{array}$ & $\begin{array}{l}\text {-Apresentação do } \\
\text { segundo grupo das } \\
\text { representações } \\
\text { elaboradas com base } \\
\text { na leitura da } \\
\text { narrativa. }\end{array}$ & $\begin{array}{l}\text { - Controle biológico e } \\
\text { sustentabilidade; } \\
\text { - O uso de inseticidas e } \\
\text { a saúde humana. }\end{array}$ & $\begin{array}{l}\text { - Apresentação oral e } \\
\text { escrita de uma cartilha } \\
\text { ilustrada; } \\
\text { - Questionamentos } \\
\text { orais pela professora e } \\
\text { demais estudantes. }\end{array}$ & $\begin{array}{l}\text { - A professora busca estabelecer } \\
\text { relações entre aquilo que os } \\
\text { estudantes falaram e os } \\
\text { conteúdos ensinados bem como } \\
\text { entre as falas dos estudantes. }\end{array}$ \\
\hline $\begin{array}{l}19 \mathrm{~min} . \\
17 \mathrm{~s}\end{array}$ & $\begin{array}{l}\text { Apresentação do } \\
\text { terceiro grupo das } \\
\text { representações } \\
\text { elaboradas com base } \\
\text { na leitura da } \\
\text { narrativa. }\end{array}$ & $\begin{array}{l}\text { - Controle biológico de } \\
\text { pragas agrícolas; } \\
\text { - Cadeia alimentar e } \\
\text { contaminação por } \\
\text { agrotóxicos. }\end{array}$ & $\begin{array}{l}\text { - Apresentação oral e } \\
\text { escrita de uma } \\
\text { paródia. } \\
\text { - Questionamentos } \\
\text { orais pela professora e } \\
\text { demais estudantes. }\end{array}$ & $\begin{array}{l}\text { - A maior parte do tempo apenas } \\
\text { a professora lançava } \\
\text { questionamentos; } \\
\text { - Os estudantes brincam entre } \\
\text { eles. }\end{array}$ \\
\hline
\end{tabular}


O episódio selecionado para análise aconteceu durante as duas primeiras intervenções (Ver Quadro 1) e se insere logo após a leitura da narrativa, especificamente quando houve apresentação das ideias pelos grupos. A intenção da professora nesse momento foi abrir espaço para questionamentos por parte dos estudantes, havendo retroalimentação das suas ideias com conceitos científicos.

Assim, após solicitação de silêncio à turma, a professora deu voz a Estudante 1, que apresentou as opiniões do seu grupo sobre a narrativa lida, dizendo que o que havia lhes chamado mais atenção no texto foi a existência de duas possibilidades para combater as pragas agrícolas da região: uma do trabalhador rural e outro científico. Sobre esse aspecto, a professora lançou questionamentos, buscando explicitar quais as possíveis origens dos conhecimentos identificados pelo grupo. Os estudantes responderam que seria a partir de estudos locais. Nesse momento, a professora pede atenção da turma para essa resposta, quando o Estudante 1 completa seu raciocínio afirmando que "O agricultor tem uma forma mais simples... ele não... ele conta nos mínimos detalhes... e se ele quisesse passar isso pro agricultor... eu acho que isso não daria certo...".

Como é possível notar, a fala do Estudante 1 revela que para ele o conhecimento do agricultor não é tão explicativo como o conhecimento expresso nos produtos vendidos para a agricultura. De fato, o conhecimento científico é descritivo, sendo inerente a um modo particular de conhecer que é a ciência, que, para tanto, utiliza linguagem própria (COBERN; LOVING, 2001).

A professora segue com a aula questionando se todas concordam com a fala do Estudante 1, porém o silêncio foi imperativo nesse momento, até que uma estudante (Estudante 2) argumenta: "[...] só que hoje já tem cooperativa que já tá ajudando os agricultores a ver diferente... não é só comprar um produto químico e botar lá... eles já mostram outras formas que custa menos e que não vai prejudicar o ambiente, a plantação e os animais".

Estudante 2 pareceu incomodar-se com a fala de Estudante 1, ao afirmar que existem cooperativas que apresentam os dois modos de conhecer para os agricultores, permitindo a ampliação de saberes voltados à agricultura. Estudante 1 completa a sua fala dizendo que são dois tipos de conhecimentos diferentes e a professora, novamente, questiona a turma se todos concordam. Houve silêncio até que Estudante 1 pergunta sobre qual seria a forma mais adequada para o agricultor utilizar na sua prática. Como resposta, os estudantes murmuraram apontando os usos químico e natural como melhores.

A professora seguiu questionando se todos concordavam e Estudante 4 disse: "[...] é o rapaz criar os animais pra combater essas pragas. Sem colocar os inseticidas". Nota-se aqui, por parte desse estudante, a preocupação com o uso de produtos químicos, cuja opinião é compartilhada por Estudante 3, quando diz: "[...] a galinha mesmo... no lugar onde tem a galinha não vai ter tantas formigas". Como é possível notar, esses estudantes demonstram conhecimentos relacionados à cadeia alimentar, o que pode significar a influência dos saberes científicos escolares sobre suas ideias.

Sobre isso, vale destacar a importância de que um dos objetivos de ensinar ciências aos jovens seja sempre a compreensão, e não a apreensão dos saberes científicos. De acordo com Cobern (2004), compreensão (entendimento) é diferente de apreensão (convicção). Segundo este autor, a compreensão não necessita de apreensão. A apreensão significa assumir uma noção como válida ou verdadeira, emitir um julgamento de verdade sobre uma proposição, e a compreensão significa o domínio sobre uma proposição (COBERN, 2004). Nessa perspectiva, o estudante poderá permanecer com sua visão de mundo, com as suas explicações agrícolas tradicionais, e as explicações científicas poderão tornar-se parte de seus pensamentos para serem empregadas nos contextos apropriados.

A professora, inquieta com as falas dos estudantes 1, 2, 3 e 4, argumenta que esses “"...] chegaram a um conceito que é o controle biológico de pragas que é feito através de que? Da introdução de um organismo que naturalmente ele consome aquele outro organismo[...]". Até aqui, é notória a tentativa da professora de estimular esses jovens à apresentação de ideias, sem respostas prontas da sua parte, o que pode ser considerado um aspecto positivo para o ensino de ciências que pretenda o diálogo intercultural, e não a imposição de saberes científicos que deverão ser sobrepostos aos saberes prévios culturais. Para Mortimer e Scott (2002), a aprendizagem não é um processo no qual ocorre a substituição das velhas concepções por novas concepções que são científicas. Ao contrário, a aprendizagem constitui 
um processo no qual ocorre negociação de novos significados num espaço comunicativo. Nesse processo, há o encontro entre diferentes perspectivas culturais e, por conseguinte, o crescimento mútuo entre elas.

Estudante 1, inquieto com a explicação que a professora acabara de dar sobre o conceito de controle biológico de pragas, diz: "Ô pró..., mas se for pensar por isso... vai colocar uma coisa que vai contaminar outra coisa... é ele vai". O Estudante 4 interrompeu a fala de Estudante 1 e disse: "Viu pró... é como ela tava falando... se colocasse o inseticida... aí a galinha vai pegar a comida e vai contaminar e depois o ser humano vai comer a galinha e pode até se contaminar.". Sobre essa fala, a professora disse: "Aí... chegou... a uma coisa interessante... que é a questão da cadeia alimentar... se a gente contamina algum item dessa cadeia... toda aquela cadeia vai ficar?". Os estudantes responderam conjuntamente: "prejudicada... Contaminada".

Estudantes 1 e 4 tentaram falar novamente, porém, suas vozes foram interrompidas pela professora dizendo: "Vocês conseguiram captar essa mensagem né? Que existe na própria natureza soluções para esses problemas que podem ser resolvidos de forma simples? E aí, vocês acham que podem existir um consenso dentro dessa questão do controle biológico?"

Estudante 2 questiona o que seria esse consenso e a professora diz: "[...] de quem está observando a natureza... de saber que existe um ser vivo que se alimenta de outro". Seguidamente, Estudante 1 diz: "Sei de coisas que pode existir..., mas... tem outras que eu não sei”. Aqui é possível perceber uma inquietação de Estudante 1 sobre a última explicação da professora, entretanto, ela não percebeu essa inquietação e segue com um novo questionamento: "Quais são as consequências do uso de inseticida comprado numa loja de produtos químicos?" e Estudante 2 então respondeu: “[...] vai acabar o ecossistema... a galinha... vai contaminar o capim... aí a vaca vai comer o capim e aí vai contaminar o leite que vai contaminar o ser humano e também vai acabar com o solo dele...".

É importante notar que a professora questionou várias vezes aos estudantes sobre o conteúdo da narrativa, entretanto, realizou poucas problematizações das suas falas com relação aos conteúdos científicos (por exemplo, os nomes científicos das espécies que servem como controle biológico). Como bem argumenta Mortimer e Scott (2002), a aprendizagem das ciências deve ser vista pelos professores como um processo de socialização dos estudantes na cultura e linguagem da ciência. Percebe-se que a professora pouco utilizou a linguagem científica nas suas comunicações com os estudantes, deixando mais para os estudantes a realização dessa tarefa.

A aula prossegue com mais questionamentos da professora sobre as possíveis dúvidas dos estudantes até que Estudante 5 disse: "Atualmente tem sido feito o controle biológico de praga... a introdução de um inimigo natural de um outro país e a para o controle de uma praga, geralmente resolve ..., mas isso demora muito... né? Depois de um ano... dois anos..."

No lugar de problematizar a fala de Estudante 5, a professora tenta completar a sua ideia: "[...] além disso você estará utilizando um organismo que não é daquele ambiente... vai colocar um animal no ambiente que não tem quem se alimente dele... o que é que vai acontecer? Aquele animal que foi usado para combater aquela praga vai".

Estudante 5 completa a fala da professora dizendo que "Vai... vai dor de cabeça também...". Aqui, Estudante 5 não esclarece o que ele quer dizer com "vai dar dor de cabeça" e a professora explica dizendo que "Vai se tornar uma praga... porque não vai ter ninguém para se alimentar". Nesse momento, entende-se que houve tentativa de interanimação de ideias na medida em que a professora dá voz e Estudante 5, que se sentindo motivado, diz paralelamente à professora: "O controle biológico se baseia na atuação dos inimigos que ocorrem naturalmente... para que seja mais efetivo é necessário evitar inseticidas químicos e propiciar alimentos para eles".

Sobre a interanimação de ideias nas salas de aula de ciências, Mortimer e Scott (2002) defendem que os professores devem promover no espaço social das salas de aula oportunidades de interações nas quais os estudantes consigam dominar as ferramentas culturais que são características das ciências. Nesse sentido, é imprescindível que o professor utilize a linguagem científica para que os estudantes consigam perceber no seu discurso o modo particular de comunicar-se da ciência que está sendo ensinada. Isso contribuirá para que os estudantes consigam demarcar a ciência de outros sistemas de saberes, especialmente dos meios socioculturais nos quais estão inseridos (COBERN; LOVING, 2001).

A professora não comentou a fala de Estudante 5 e, novamente, voltando-se para os 
grupos questionou se eles tinham dúvidas. Nesse momento, Estudante 5 continuou a sua fala dizendo: "[...] isso aqui professora... se a gente tem uma praga... a gente pode colocar um sapo na área onde a gente quer...". A professora lhe questiona o porquê e Estudante 6 diz: "[...] o sapo já vai se alimentar daqueles [...]". A professora diz, interrompendo-o: "Porque as pessoas já sabem que a alimentação do sapo [...]" e Estudante 6 argumenta: "[...] a gente pode pegar o sapo, pega o sapo e coloca numa sacola e chegando na sua agricultura e aí ele vai se alimentar das pragas [...]". Então, a professora diz à turma: "Vocês conseguiram ver que existem duas formas? O que vocês acham que é melhor, introduzir um material não biológico que não é sustentável ao meio ambiente? Ou introduzir um sistema que que não prejudique a cadeia alimentar?".

Como é possível notar na fala da professora, ela parece reunir todas as ideias trabalhadas nesse momento, tentando sintetizá-las em prol de que os estudantes escolham qual seria a forma mais adequada para o meio ambiente e seu desenvolvimento, o controle natural ou químico das pragas agrícolas. Tal atitude é extremamente relevante para que diálogos sejam estabelecidos, porque o diálogo deve constituir-se da exposição de razões, tanto por parte da ciência como por parte dos demais saberes culturais presentes. Assim, acredita-se que a exposição de razões sem imposições de saberes deixa os estudantes livres para escolherem quais saberes lhe são mais apropriados no dado momento e contexto das suas vidas.

Estudante 6 responde à pergunta da professora afirmando que "A última é melhor, mas se for em grupo... a gente acaba com as praga toda. Se tiver uma roça grandona, eu usar na minha parte e a minha colega na dela, aí acaba com tudo, né?".

Sobre as falas da professora e de Estudante 6, é interessante notar um aspecto importante relacionado aos conteúdos de ensino da biologia com relação ao meio ambiente, particularmente agrícola, que é a noção de desenvolvimento sustentável. Nesse momento, percebe-se que a professora conseguiu conduzir esse estudante a refletir sobre o uso apropriado do solo para suprir as necessidades dos agricultores sem, contudo, comprometer a capacidade de atender às necessidades de outros ou de futuras gerações.

Dando continuidade à aula, a professora apresenta uma nova problematização: "E se a colega ao invés de usar o controle biológico... decidir utilizar um controle que seja industrializado?", e Estudante 6 responde: "O animal morre...”. A professora não problematiza essa fala de Estudante 6 buscando entender as razões da sua afirmativa e diz: "Vocês perceberam isso? Que esse tipo de controle biológico tem de ser feito a partir de quê? De toda aquela comunidade. Se um faz de um jeito e outro faz de outro... então... o efeito vai ser mais? Como vai ser esse efeito?".

Estudante 4 disse não entender a explicação da professora e ela explica-lhe dizendo: "Se as pessoas não entrarem em um consenso quanto ao tipo de controle de pragas de uma região, um vai usar o controle biológico e outro o veneno. Então, é muito importante que as pessoas passem uns para os outros as melhores soluções".

A professora, deslocando-se por entre os grupos, continuou perguntando se alguém teria algo mais para falar. Como ninguém respondeu a sua pergunta, ela voltou-se para o grupo que estava comentando a narrativa e solicitou-lhes uma conclusão final, dizendo: "Vamo ouvir gente a conclusão do grupo? "

Estudante 6, lendo o que o seu grupo havia escrito, disse:

[...] existem várias maneiras de combater as pragas que não degradando o meio ambiente com queimadas... desmatamento... usando produtos adequados para ela... alimentação das pragas... sabendo que aquele produto pode causar para a natureza e para os animais... preste atenção mais com o que está lidando... mas antes de aplicar qualquer produto nos insetos que estão prejudicando a plantação ou a saúde das suas crianças.

A professora, em meio ao intenso barulho na sala de aula, dá inicio à finalização da aula, solicitando reflexões sobre o conteúdo abordado, enquanto os estudantes continuaram com intenso barulho: "Então há uma concordância... o agricultor pensa... analisa ates de tomar qualquer atitude com relação aquilo que está prejudicando... e a solução pode estar dentro do próprio conhecimento dele...".

Por fim, é importante discutir o intenso barulho ocorrido durante o episódio selecionado. É possível que os estudantes tenham ficado empolgados pelo fato de estarem participando de uma aula atípica, a qual requereu por todo tempo as suas participações com respostas. Sobre esse 

trabalho colaborativo

fato, vale considerar que nos diálogos estabelecidos nas aulas de ciências é fundamental que os estudantes sejam motivados à participação, visto que isso poderá favorecer argumentações das suas partes. Todavia, não basta que eles falem, é preciso que as suas falas sejam problematizadas para que ocorra a negociação de significados.

A professora de biologia, segundo ela mesma, enfrenta problemas ligados ao ambiente de trabalho no qual está inserida que dificultam a sua prática pedagógica, no sentido de problematizar as participações dos estudantes durante as suas aulas. Como exemplo ela cita a carga horária e excessiva quantidade de conteúdos científicos a serem cumpridos durante o ano letivo, além da própria cultura escolar que não está voltada para esse tipo de aula, estando acostumada com a pedagogia transmissiva. Isso lhe causou preocupações durante as intervenções pedagógicas acima apresentadas, razão pela qual acredita não ter alcançado uma abordagem comunicativa dialógica, mas, sim, de autoridade. Para ela, houve tentativas de que os alunos falassem, mas, ao final, prevaleceu a sua voz com explicações científicas.

\section{Conclusões}

As análises sobre o episódio selecionado das intervenções pedagógicas realizadas pela professora de biologia revelaram que houve tentativas de diálogos entre os saberes culturais dos estudantes agricultores e não agricultores com os conteúdos científicos da biologia escolar. Essa afirmativa decorre do fato de que a professora requereu por todo tempo as falas desses sujeitos, sem unilateralidade, o que poderia constituir um ensino totalmente transmissivo e baseado na superioridade epistemológica da ciência. Entretanto, não é possível a afirmativa de que a professora realizou uma abordagem comunicativa do tipo dialógica (MORTIMER; SCOTT, 2002), porque as falas dos estudantes não foram problematizadas, de maneira que fosse possível o estabelecimento de relações de semelhanças e/ou de diferenças entre os saberes científicos escolares e os saberes culturais dos estudantes (BAPTISTA, 2007).

Entende-se que o campo de formação de professores, seja para a universidade ou para a escola, é complexo diante da multiplicidade de elementos envolvidos nesses espaços, sendo um grande desafio para todos os participantes. No presente estudo, foi possível constatar algumas dificuldades que permearam as atividades pedagógicas da professora de biologia, particularmente a indisciplina. Segundo a professora de biologia, é possível que o comportamento dos estudantes tenha relação direta com a cultura escolar da qual participa, que é tecnicista e não está acostumada à realização de atividades que envolvam a participação direta dos estudantes. Sendo assim, é possível que eles não tenham levado à sério as aulas, encarando-as como uma brincadeira. Ainda segundo a professora de biologia, o comportamento dos estudantes terminou por confundir a sua tentativa de diálogo durante as aulas. Sobre esse fato vale considerar que os professores antes de serem profissionais são seres humanos que, como tal, recebem influências que interferem nas atividades que desenvolvem e suas formações.

Assim, os resultados obtidos a partir da construção e aplicação de um recurso e sequência didática com estudantes do ensino médio de um colégio estadual da Bahia permitiram às autoras repensar aspectos voltados às interações dialógicas que possam ocorrer durante os processos de ensino e da aprendizagem da biologia. De igual forma, para a pesquisa científica com relação à formação inicial e continuada de professores de ciências para a diversidade cultural. Sobre as interações dialógicas, entende-se que o trabalho colaborativo ora apresentado contribuiu para a afirmativa de que um professor torna-se investigador na medida em que reflete e modifica as suas atividades didáticas para que melhorias aconteçam. A professora de biologia pôde repensar e replanejar a sua ação didática no sentido de que não basta apenas solicitar a presença das falas dos estudantes durante as tentativas de diálogos, a partir de perguntas soltas do tipo "o que acham?", "Alguém tem alguma coisa para falar?" e, logo após isso, apresentar o discurso científico. Dialogar requer ir além disso. Requer a problematização das falas, para que os interlocutores exponham seus saberes e razões inerentes aos seus meios socioculturais, os quais poderão ter, ou não, relações com a ciência ensinada. Porque isso gerará negociação de significados, podendo contribuir para que esses sujeitos tenham suas visões de natureza ampliadas com conhecimentos científicas.

No que tange a pesquisa científica voltada para a formação inicial e continuada, o estudo permitiu identificar a necessidade de que o trabalho colaborativo entre a universidade e a escola não envolva apenas o pesquisador e o 
professor de ciências, mas, também os licenciandos e os estudantes da escola. Para as autoras deste artigo, pensar em melhorias na formação continuada também requer pensar a formação inicial do professor e os sujeitos da aprendizagem. A formação inicial porque o envolvimento dos licenciandos contribuirá para que os futuros professores assumam desde cedo uma postura de investigador podendo refletir sobre a prática pedagógica de maneira antecipada, antever dificuldades e encontrar soluções conjuntas com os professores que já atuam na escola. Além disso, contribuirá para a ampliação dos saberes desses professores, especialmente teóricos, que vão sendo renovados constantemente e que muitas vezes são afastados das escolas.

Considera-se que o projeto que dará origem à pesquisa colaborativa deverá ser elaborado entre formadores de professores, professores de ciências e licenciandos, sempre partindo de problematizações que envolvam as realidades culturais dos estudantes e da própria ciência ensinada. Isso porque compreende-se que ações colaborativas entre os vários sujeitos que integram a universidade e a escola permitirá progredir em direção à aprendizagem da docência em prol da aprendizagem científica por parte dos estudantes, por realizarem compartilhamento de ideias, conhecimentos, práticas e opiniões em busca de soluções para esses problemas.

\section{Notas}

1 Para a Sociedade Internacional de Etnobiologia (ISE, 2012), a etnobiologia é o estudo das complexas relações que existem entre seres vivos e sistemas culturais, tanto nas sociedades passadas como atuais. No presente estudo as pesquisas etnobiológicas foram levadas em conta por permitir a investigação e compreensão dos saberes culturais dos estudantes dentro e/ou fora do contexto escola (BAPTISTA, 2007).

\section{Referências}

AMARAL, E. M. R.; MORTIMER, E. F. Uma metodologia para análise da dinâmica entre zonas de um perfil conceitual no discurso da sala de aula. In: SANTOS, F. M. T. e GRECA, I. M. (Orgs.). A pesquisa em ensino de ciências no
Brasil e suas metodologias. Ijuí: Editora UNIJUÍ, 2006, p. 239-296.

BAPTISTA, G. C. S. A contribuição da etnobiologia para o ensino e a aprendizagem de ciências: estudo de caso em uma escola pública do estado da Bahia. Dissertação de Mestrado, Programa de Pós-graduação em Ensino, Filosofia e História das Ciências, Salvador: Universidade Federal da Bahia - Universidade Estadual de Feira de Santana, 2007.

BAPTISTA, G. C. S. Do cientificismo ao diálogo intercultural na formação do professor e ensino de ciências. Interacções, v. 31, p. 28-53, 2014.

BARDIN, L. Análise de conteúdo. Lisboa: Edições 70, 2006.

CARVALHO, A. M. P. Uma metodologia de pesquisa para estudar os processos de ensino e aprendizagem em salas de aula. In: SANTOS, F. M. T. dos \& GRECA, I. M (Org.). A pesquisa em ensino de ciências no Brasil e suas metodologias. Ijuí: Editora UNIJUí, 2006, p. 13-48.

COBERN, W. W. Apples and oranges: a rejoinder to Smith and Siegel. Science Education, v. 13, n. 6, p. 583-589, 2004. DOI: 10.1023/B:SCED.0000042856.33782.7b.

COBERN, W. W.; LOVING, C. C. Defining science in a multicultural world: Implications for science education. Science \& education, v. 85, p. 50-67, 2001. DOI: 10.1002/1098237X(200101)85:1<50::AID-SCE5>3.0.CO;2-G.

CONRADO, D. M.; NUNES-NETO, N. F.; ELHANI, C. N. Argumentação sobre problemas socioambientais no ensino de biologia. Educação em revista, v. 31, n. 1, p. 329-357, 2015. DOI: 10.1590/0102-4698125846.

DIBATTISTA, L.; MORGESE, F. Introducing History (and Philosophy) of Science in the Classroom: A Field Research Experience in Italy. Science \& education, v. 22, n. 3, p. 543-576, 2013. DOI:10.1007/s11191-012-9436-X

EL-HANI, C. N. Por que a etnobiologia e a etnoecologia são importantes? Uma resposta do ponto de vista da educação. In: COSTA-NETO, E. 
M. \& SOUTO, F. J. B. (Orgs.). Anais do I encontro baiano de etnobiologia e etnoecologia. Feira de Santana: Universidade Estadual de Feira de Santana, 2001, p. 91-108.

EL-HANI, C. N.; MORTIMER, E. F. Multicultural education, pragmatism, and the goals of science teaching. Cultural studies of science education, v. 2, n. 3, p. 657-702, 2007. DOI: 10.1007/s11422-007-9064-y.

GALVÃO, C. Narrativas em educação. Ciência \& educação, v. 11, n. 2, p. 327-345, 2005. DOI: 10.1590/S1516-73132005000200013.

GIL-PÉREZ, D.; MONTORO, I. F.; ALÍS, J. C.; CACHAPUZ, A.; PRAIA, J. Para uma imagem não deformada do trabalho científico. Ciência \& educação, v. 7, n. 2, p. 125-153, 2001. DOI: 10.1590/S1516-73132001000200001.

ISE (Sociedade Internacional de Etnobiologia). Disponível em: < http://ethnobiology.net/about/>. Acesso em: 4 abr./ 2012.

JONES, M. M. Collaborative partnerships: a model for science teacher education and professional development. Australian journal of teacher education, v. 33, n. 3, 2008. DOI: 10.14221/ajte.2008v33n3.5.

LOPES, A. R. C. Pluralismo cultural em políticas de currículo nacional. In: MOREIRA, A. F. B. (Org.). Currículo: políticas e práticas. Campinas: Papirus, 1999. p. 59-80.

MARTINS, I. Dados como diálogo: construindo dados a partir de registros de observação de interações discursivas em salas de aula de ciências. In: SANTOS, F. M. T. dos \& GRECA, I. M. (Org.). A pesquisa em ensino de ciências no Brasil e suas metodologias. Ijuí: Editora UNIJUÍ, 2006, p. 297-321.

MATTHEWS, M. História, filosofia e ensino de ciências: a tendência atual de reaproximação. Caderno catarinense de ensino de física, v. 12, n. 3, p. 164-214, 1995.

MORTIMER, E. F.; SCOTT, P. Atividade discursiva nas salas de aula de ciências: uma ferramenta sociocultural para analisar e planejar o ensino. Investigações em ensino de ciências, v. 7 , n. 3, p. 283-306, 2002.

OSBORNE, J.; ERDURAN, S.; SIMON, S.; MONKIN, M. Enhancing the quality of argument in school science. School science review, v. 82, n. 301, p. 63-70, 2001.

PONTE, J. P. Investigar a nossa própria prática: uma estratégia de formação e de construção do conhecimento profissional. PNA: revista de investigación en didáctica de la matemática, v. 2, n. 4, p. 153-180, 2008.

ROSA, M. I. de F. P. dos S.; SCHNETZLER, R. P. A investigação-ação na formação continuada de professores de ciências. Ciência e educação, v. 9, n. 1, p. 27-39, 2003. DOI: 10.1590/S151673132003000100003 .

SCHÖN, D. The reflective practitioner. New York: Basic Books, 1983.

\section{Sobre as autoras}

Geilsa Costa Santos Baptista é Professora Adjunta da Universidade Estadual de Feira de Santana (BA) e no Programa de Pós-Graduação em Ensino, Filosofia e História das Ciências. Doutora e mestre em Ensino, Filosofia e História das Ciências pela mesma Universidade. Especialista em Saúde Aplicada ao Ensino de Biologia e licenciada em Ciências Biológicas também pela Universidade Estadual de Feira de Santana.

Dirlane Gomes E Silva é Mestre em Botânica pela Universidade Estadual de Feira de Santana. Licenciada em Ciências Biológicas pela mesma Universidade. Especialista em Sistemática de Angiospermas com ênfase na Flora do Nordeste. Professora da Rede de Ensino Básico do Estado da Bahia. 
Recebido em dezembro de 2016.

Aprovado em fevereiro de 2017. 